\title{
A IDENTIDADE DE PROFESSORES NA REALIDADE DE ESCOLAS RURAIS DA MATA MERIDIONAL DE PERNAMBUCO
}

\section{THE IDENTITY OF TEACHERS IN REALITY RURAL SCHOOLS OF THE SOUTHERN MATA OF THE PERNAMBUCO}

\author{
LA IDENTIDAD DE LOS MAESTROS EN LA REALIDAD DE \\ LAS ESCUELAS RURALES DEL MATA SUR DE PERNAMBUCO
}

Tarcísio Augusto A. da Silva

Sociólogo (UFRPE), Msc. em Serviço Social (UFPE), doutorando em Sociologia (UFPE), professor da FAESC - Faculdades da Escada (PE).

E-mail: deescada@yahoo.com.br

Claudevânia Rijo do Carmo

Valdiclere Vicente da Silva

Pedagogas formadas pela FAESC - Faculdades da Escada (PE)

\section{Resumo}

Este trabalho tem por objetivo identificar os fatores que inviabilizam a construção da identidade dos educadores do campo não atrelados aos Movimentos Sociais. Para que nosso objetivo pudesse ser atingido inicialmente realizamos uma pesquisa bibliográfica. Dando continuidade ao trabalho utilizamos como procedimento e instrumental para coleta de dados a análise documental; entrevistas semi-estruturadas, efetuadas com oito professores da zona rural e observação direta assistemática da realidade de trabalho dos professores nas escolas rurais. A análise e discussão dos dados nos possibilitou na constatação dos fatos que têm gerando uma crise na construção da identidade profissional do professor, crise esta que tem se associado a práticas desvinculadas com a realidade dos discentes e da comunidade da zona rural. Por fim, nossas hipóteses foram confirmadas, pois pudemos identificar os fatores que inviabilizam a construção da identidade do educador do campo não atrelado aos Movimentos Sociais, ao constatamos que a formação continuada oferecida a estes professores pelo município não prioriza a 
valorização e formação específica para construção e fortalecimento da identidade dos docentes, que as condições de trabalho não favorecem ao processo de construção de uma identidade positiva e que existe de fato uma crise de identidade dos educadores do campo não ligados aos Movimentos Sociais associados à desvalorização social da profissão.

Palavras-chaves: identidade profissional, crise do educador do campo, crise da identidade.

\begin{abstract}
The aim of this work is to identify the factors, which damage the construction of the rural educators' identity, who are not participating in Social Movements. Aiming at the achievement of the work, it was initially done a bibliographical research. The following part was to use as a procedure and an instrument, the data collecting, the documental analysis, and semi-structured interviews done with eight teachers in the rural zone, the rural zone teachers assistematic direct interview of the reality of the work. The analysis and the discussion gave the opportunity to verify the facts, which have been generating a crisis of teacher's professional identity construction, that crisis which has been associated to the non vinculated practices with the students reality and the rural zone community. Finally, the hypotheses were confirmed, consequently it was identified that the factors which damage the rural educator's construction of the identity without association to the Social Movement, when it was verified the continuous formation offered to those teachers by the city government, does not prioritize the valorization and specific formation to the construction and enhancement of the teachers identity. The work conditions do not facilitate the process of construction of a positive identity and which there is a really rural educators crisis of identity without connection to the Social Movements associated to the social devalorization of the profession.
\end{abstract}

Keywords: Professional identity, rural educator crisis, identity crisis.

\title{
Resumen
}

Este trabajo tiene por objetivo identificar los factores que imposibilitan la construcción de la identidad de los educadores del campo que no hacen parte de ningun Movimiento social. Para que nuestro objetivo pudiera ser cumplido, inicalmente hicimos una pesquisa bibliográfica. A continuacion utilizamos como procedimientos e instrumental para la colecta de los datos y análisis de los documentos y entrevistas semiestructuradas. tuvimos, en la ocasión, a ocho profesores que particparon como entrevistados en el pueblo y observación directa asistemática de la realidad de trabajo de los profesores en las escuelas del pueblo. El análisis y el estudio de los datos nos han posibilitado ver que existe un problema en la construccion de la identidad profesional del profesor, crisis que está asociada a las prácticas aisladas de la realidad de los alumnos y de la comunidad que vive en el pueblo. Por fin, nuestras hipótesis fueron confirmadas, pues identificamos los factores que imposibilitan la construccion de la identidad del educador del pueblo que no está vinculado a ningn movimiento social. Hemos percibido tambien que la formación ofrecida por el gobierno a estos profesionales no valora la formación de una identidad profesional fuerte. Que las condiciones de trabajo no facilitan el 
proceso de construcción de una identidad positiva y que existe, de hecho, una crisis de identidad de los educadores del campo que no hacen parte de ningun movimiento social que está ligada a la desvaloración de la profesion en el medio social.

Palabras-clave: Identidad profesional, crisis del educador del pueblo, crisis de identidad

\section{Introdução}

A educação no campo, como hoje entendemos o processo de socialização formal de conhecimentos e valores construídos socialmente e transmitidos no âmbito da escola para a população do rural, é resultado das lutas por direitos preconizadas pelos movimentos sociais no rural brasileiro, que dentre outras reivindicações trabalham para assegurar uma escola pública de qualidade, um ideal que não se encontra concretizado em sua plenitude, em decorrência dos interesses das elites agrárias que insistem em manter a submissão de parte desta população à custa da ignorância.

Um dos traços fundamentais na trajetória de construção da educação no campo, contrária a perspectiva de educação rural, foi à realização da I Conferência Nacional por uma Educação do campo (1998) e a implementação das Diretrizes Operacionais para a Educação Básica das Escolas do Campo, trazendo de volta as discussões em torno da consolidação de políticas públicas voltadas para os interesses e anseios daqueles (as) que foram por muitos anos esquecidos pelo poder público brasileiro.

Neste processo de valorização e melhoria da oferta de ensino, os discursos têm demonstrado a importância que deve ser dada aos educadores na construção de sua própria identidade, uma identidade vinculada aos projetos educativos do campo uma vez que, "[...] em muitos lugares elas e eles têm sido sujeitos importantes da resistência no campo, especialmente nas escolas". (CALDART, 2002). Uma proposta a ser destacada é a do MST (Movimento dos Trabalhadores Rurais Sem Terra), no qual seus educadores se identificam com a luta do movimento, tornando-se sujeitos atuantes para democratização do ensino, trabalhando com os currículos desenvolvidos para e no MST, através de uma pedagogia da terra em movimento, segundo Roseli Caldart (2002).

Por outro lado, é necessário perceber que a educação no campo não é uma realidade difundida e vivenciada em todo o país, estando em muitos casos persistindo uma proposta de educação pautada no desconhecimento ou desvalorização do contexto 
sociais dos indivíduos. Neste sentido, vários aspectos da sociabilidade dos educandos se vêem comprometidas, ficando a educação dispensada para o campo como um dos elementos que mais fortemente tem colaborado para a permanência do êxodo rural, mesmo este tendo se reduzido nos últimos anos.

No caso especifico dos professores que atuam em escolas rurais cuja identidade não são oriundas e nem construídas a partir da integração com os movimentos sociais um outro elemento se revela, pois como construir uma identidade positiva sobre a profissão sem referenciais locais ou condições de trabalho que tragam uma percepção sobre o campo como um "lugar de vida"?

Este é um problema a ser superado pelos professores do campo, visto que a superação deste processo é fundamental para sua afirmação como sujeito transformador dentro do grupo social em que estão inseridos e contribuindo para o desenvolvimento dos educandos de forma significativa, pois, podemos observar que "a identidade não é um dado imutável, nem externo, que possa ser adquirido, mas é um processo de construção do sujeito historicamente situado" (PIMENTA, 2002).

Construir uma identidade requer que os professores estejam cientes que tanto a superação das barreiras postas a uma prática educativa coerente, quanto à necessidade de recriar suas práticas estão fortemente ligadas ao fortalecimento da sua profissão enquanto educador e do lugar da educação para o processo de transformação da realidade do campo.

Portanto, partimos do princípio de que se os educadores ligados à educação no campo, entendida aqui enquanto aquela promovida pelos movimentos sociais, possuem uma identidade positiva sobre a profissão fundada na experiência de luta por direitos, construída na sua inserção com o movimento, os educadores de escolas de educação rurais não já não têm a mesma percepção sobre o assunto, de modo estes têm percebido a profissão como uma opção de trabalho de mais fácil inserção para a região aqui estudada.

Todavia, ao buscar analisar a realidade da educação ofertada nas escolas rurais no município da Gameleira em Pernambuco mais que compreender a identificação dos professores com a profissão vislumbramos entender que variáveis tem contribuído para que a sua percepção sobre a aquilo que ele faz seja tão negativa. 
Sendo assim, a questão que orienta este trabalho é: quais os fatores que inviabilizam a construção da identidade dos educadores do campo não atrelados aos Movimentos Sociais?

Ao pensar tais elementos traçamos como objetivo geral deste estudo: Identificar os fatores que inviabilizam a construção da identidade dos educadores do campo não atrelados aos Movimentos sociais. Conseqüentemente os caminhos que percorremos para atingir tal meta estão explicito em nossos objetivos específicos: a)Analisar os programas de formação continuada oferecida aos educadores do campo; b)Identificar as condições de trabalho dos professores do campo.

A abordagem metodológica adotada considerou as características do objeto de estudo definindo a pesquisa enquanto qualitativa, uma vez que: "na pesquisa social, estamos interessados na maneira como as pessoas espontaneamente se expressam e falam sobre o que são importantes para elas e como elas pensam sobre as suas ações e as dos outros" (BAUER, GASKELL \& ALLUM, 2002, p.21).

Por sua vez, utilizamos como procedimento e instrumental para a coleta de dado, a entrevista semi-estruturada, que é caracterizada pela "formulação da maioria das perguntas previstas com antecedência e sua localização é provisoriamente determinada". (COLOGNESE e MÉLO, 1998). Foram entrevistados 08 (oito) professores que atuaram nas escolas rurais, no período de 19/05 à 02/06/2007. O uso das entrevistas como técnica para coleta de dados se justificou, pois "fornece os dados básicos para o desenvolvimento e a compreensão das relações entre os atores sociais e sua situação" (BAUER, GASKELL \& ALLUN, 2002, p.65). A intenção foi, através deste instrumento, comprovar a existência de fatores que inviabilizam a construção da identidade do educador do campo do município da Gameleira - PE.

Realizamos também a observação direta assistemática da realidade do trabalho dos professores nas escolas rurais de 28/05 à 01/06/07. Este tipo de observação "é a que se realiza, sem planejamento e sem controle anteriormente elaborados, como decorrência de fenômenos que surgem de imprevisto" (RUDIO 1998, p. 41).

Além das entrevistas realizadas e das observações feitas, buscamos também proceder a uma análise documental da proposta de formação continuada de professores dos anos de 2005 e 2006, junto à secretaria de educação do município de Gameleira. 
Quanto à análise dos dados, as informações obtidas por meio das entrevistas foram analisadas sob uma perspectiva de compreensão da crise de identidade profissional dos profissionais da educação norteados por Silva (1995), Souza (1996), Guimarães (2004), e Meksenas (2003).

\section{Identidade pessoal e profissional: uma discussão introdutória}

A identidade é algo inerente ao homem, ele tem em sua essência características que indicam o seu "eu" enquanto ser único. Claro que a construção da identidade pessoal sofre influências a partir do momento em que o ser começa a interagir com o mundo em seus vários aspectos: político, econômico, religioso, cultural, e em sua interação com o outro por meio das socializações das especificidades humana que circundam cada ser. Carrolo apud Guimarães (1997, p. 59) apresenta esta problemática da seguinte maneira:

A construção da identidade pessoal é um processo complexo que se dá em toda existência do homem, na interação com o mundo e com o outro, uma vez que os indivíduos agem e interagem de formas pessoais em relação ao processo de socialização e este tem resultados também específicos na história de cada um.

Diante do exposto temos a convicção de que o homem é um si mesmo unitário (LOPES, 2003), que consegue construir seus vários meios de desenvolver sua essência, de estabelecer suas relações ao longo de sua existência, no transcorrer de seu processo histórico.

Quando se fala em identidade, lembramos da identidade pessoal porque é a que todos temos consciência enquanto ser humano do que somos, mas existe outra identidade em que também estamos inseridos enquanto seres que vivemos em grupo, enquanto seres sociais, não por sermos condicionado ou determinado pelo meio social, mas por sofrermos influências por meio da sociedade na construção de nossa capacidade de pensar e agir, a identidade social.

A identidade social abrange: gênero, sexualidade, raça, idade e profissão, no entanto queremos nos deter nesta última: a identidade profissional, a qual é construída a partir da significação social da profissão, tal qual afirma Pimenta: 
Uma identidade profissional se constrói [...] a partir da significação social da profissão; da revisão constante dos significados sociais da profissão; da revisão das tradições [...] de suas angústias e anseios, do sentido que tem em sua vida o ser professor. (2002, p.19).

Diante esta colocação de Pimenta podemos perceber que a identidade profissional está relacionada a aspectos mais específicos como as formas e estratégias da configuração do profissional na sociedade, de seus saberes e de seu desenvolvimento profissional, como também aos aspectos que estão ligados as disposições pessoais frente à profissão, de suas expectativas em pertencer a um grupo que têm basicamente a mesma maneira de produção da existência.

\section{Identidade do professor e o surgimento de uma crise}

Em todo contexto educacional o professor trás consigo traços fundamentais que possibilitam a identificação de sua identidade profissional, e estas são traduzidas a partir de suas manifestações diárias, sendo ela também resultado das diversas socializações que teve contato durante toda a sua vida, tais influências podem contribuir no processo de construção e fortalecimento de sua identidade.

Nesse sentido, cumpre destacar as idéias de Pimenta (2002), quando afirma que a identidade se constrói a partir da significação social da profissão, pelo significado que cada professor enquanto ator e autor confere as atividades docentes do seu cotidiano, de seus saberes, de suas angústias e anseios, do sentimento que tem em sua vida o ser professor. Assim, todas as manifestações realizadas pelo educador, são traços fundamentais de sua identidade e que possibilitam as outras pessoas fazerem uma diferenciação com as demais profissões existentes. Nesta direção, surgem pensamentos semelhantes ao de Pimenta quando traça a identidade do educador, é o caso de Silva quando afirma que a construção/afirmação da identidade:

Ocorre nos movimentos que o sujeito consegue realizar em direção aos desafios do mundo. Nesse movimento caminhada, necessariamente envolvendo ações, relações e interações sociais, ocorrem situações de identificação e diferenciação para a consciência do sujeito. (1995, p. 32). 
Se uma identidade é constituída destes fatores a mesma não se torna uma tarefa fácil a compreensão deste processo tão complexo, visto que a profissão de professor encontra-se numa crise que tende a se generalizar, principalmente no que se refere a forma como a profissão vem sendo representada na sociedade brasileira, representações estas que direcionam para o desprestígio e degeneralização do professor e de suas virtudes, o que amplia e intensifica ainda mais o problema. Portanto, a crise de identidade tem sua origem em diversos fatores políticos, culturais e econômicos, o que interfere diretamente nas representações construídas pela sociedade frente ao profissional da educação, ou seja, o professor. Para Meksenas "as causas da crise de identidade são diversas: conflitos na instituição de trabalho, baixos salários, sentimentos de incertezas e insegurança" (2003).

Um problema que vem afligindo os professores e tem tomado grandes proporções durante os últimos anos, refere-se à violência dos alunos em sala de aula, violências estas que são manifestadas através de agressões físicas e verbais. Tal acontecimento traz como conseqüência a aversão dos professores a sala de aula, visto que este ambiente não mais proporciona segurança e motivação para o exercício de sua profissão. Estes problemas têm se agravado ainda mais em decorrência da crise da autoridade familiar, de maneira que a função de educar é atribuída apenas à escola e professores, introduzida muita vezes na forma de um currículo oculto.

Diante desta realidade, ainda existem outros fatores que tendem a direcionar para a desprofissionalização do professor, dentre eles pode-se destacar o acúmulo da jornada de trabalho em que o profissional tenta suprir os baixos salários dando aulas em outras instituições ou até mesmo em outros empregos fora da área de atuação. Essas situações são denunciativas da desvalorização dos princípios e finalidades reais da profissão, do desprestígio profissional e o conseqüente abandono escolar (VEIGA, 1999), tornando-se em algo determinante para aferição de uma crise profissional do professor. Sem contar com as instabilidades de alguns docentes, resultante de vínculos empregatícios temporários, próprios da precarização das relações de trabalho o que dificulta o processo de definição a identidade. Segundo Libanêo, "esse quadro se reflete no exercício profissional dos professores, cai seu interesse pela autoformação, pela busca de ampliação de cultura geral [...] rebaixa seu nível de expectativa em relação aos aspectos de desenvolvimento pessoal e profissional" (2001, p.90). 
Em outras palavras, o professor vive e sobrevive de uma profissão, cuja imagem não oferece nenhuma referência positiva que os possibilitem resgatar seu prestígio, seus valores e a acima de tudo a essência que envolve o ser professor, estas situações somadas ao estado de desconfiguração, pessimismo e baixo auto-estima generalizadas, são realidades que afetam e ampliam a crise de identidade deste profissional.

\section{Imagens e mitos na crise de identidade do educador}

Em todo contexto histórico brasileiro o professor carregou consigo imagens e mitos frente a sua profissão e estas por sua vez permanecem até os dias atuais, interferindo no processo de construção e efetivação de sua identidade. Para Guimarães "não é fácil identificar-se com uma profissão cuja imagem não oferece referência positivas, comuns e mobilizadoras" (2004, p.60). Vinculadas a estas questões criam-se concepções que confundem o professor enquanto profissional da educação, uma vez que seus direitos, seus valores são esquecidos, sobressaindo apenas às representações negativas, o que colabora para o processo de desconfiguração do ser professor.

Dentre as concepções que circundam este profissional uma delas refere-se a discussão em torno da distinção entre ser "professor" e ser "educador", uma questão que ganhou espaço durante algumas décadas e gira em volta das relações entre competência técnica e compromisso político do educador (PEREIRA, 2000), ou seja, o educador seria aquele cuja formação ultrapassa os limites da escola, se destacando pelo o ato de educar e não apenas pelo o ato de ensinar.

Um outro discurso bastante evidenciado durante muitos anos, refere-se ao mito existente em que o magistério seria uma ocupação mais adequada para mulheres, resultado de um longo processo o qual se tinha a docência como sacerdócio e vocação, o que refletiu também na imagem do magistério como atividade maternal, visto que as mulheres já possuíam habilidades suficientes nos cuidados com a criança. Tais acontecimentos originaram numa imagem bastante difundida nos dias atuais, é o caso em que as professoras são tidas como "tia", certamente esta ligação dar-se através do mito da docência como atividade maternal, em que a criança relaciona a professora como uma extensão de sua família. Nessa linha de pensamento Veiga e Cunha afirmam que: 
A presença feminina na profissão docente [...] é um fenômeno universal. Certamente, essa relação histórica se relaciona com a combinação que se dá entre maternidade e catequese, tendo como referencial o objetivo da educação e da escola. (1999, p.138).

Vinculadas a estas questões criou-se um alto grau de discriminação quando se referia ao homem como professor; embora isto pareça algo extremamente normal em nossos dias, foi alvo de grande resistência e preconceito na sociedade brasileira, pois o homem que submetesse ao exercício do magistério estaria colocando sua masculinidade em jogo. Uma outra imagem muito forte nos dias atuais e que afeta principalmente os professores do gênero feminino é o fato delas serem consideradas provedoras do lar, ou seja, chefe de família, o que culturalmente é algo destinado exclusivamente aos homens. Isto se observa porque a professora em geral ao ter um salário fixo, garantido,que as situações de desemprego no âmbito familiar sejam superadas graças ao seu trabalho enquanto docente.

Associando-se a isto, temos ainda a falta de credibilidade e desprestígio que este profissional vem tendo na sociedade, afetando ainda mais a sua imagem, e conseqüentemente determinando situações de pessimismo, de baixa auto-estima e descrença na educação brasileira. Dessa forma, o mesmo começa a desacreditar na sua profissão, chegando até mesmo negar-se como professor em algumas situações vivenciadas por ele na sociedade.

\section{Identidade do educador do campo}

A educação no campo sempre foi cercada por conflitos que impossibilitavam seu desenvolvimento, porém muitos avanços deram conta de suprir ao menos teoricamente as principais necessidades educacionais dos sujeitos que vivem e sobrevivem do campo. Tais acontecimentos só puderam efetivamente acontecer com as intervenções dos Movimentos Sociais e podem ser encontradas nos documentos da I Conferência Nacional por uma Educação do Campo e nas Diretrizes Operacionais para Educação Básica nas Escolas do Campo.

Nesse sentido, os discursos têm demonstrado a importância dos educadores e de sua identidade, uma vez que esta contribui de forma significativa para o 
desenvolvimento do campo e conseqüentemente a qualidade de ensino oferecida aos seus sujeitos. Assim, cabe ressaltar o pensamento de Molina “[...] educador do campo é aquele que contribui para o processo de organização do povo". É pensando nesta perspectiva de uma nova identidade do educador do campo que Roseli Salete (2002), defende a necessidade de políticas e de projetos de formação dos educadores do campo.

Desta maneira, é de extrema necessidade que se desenvolva uma formação que tenha em sua essência um compromisso com a causa do campo, despertando nos professores um novo olhar diante do trabalho nas escolas rurais. Uma formação específica direcionada a ajudar aos docentes a compreenderem seu papel dentro da comunidade, desenvolvendo um trabalho unindo escola e comunidade, quebrando com paradigmas que vem perpassando a história e que tem por base concepções neoliberais que não estão preocupados com a qualidade de educação que é destinada a população urbana, quiçá a comunidade do campo. Mas, se existirem políticas direcionadas a atender as necessidades dos educadores do campo, de fato haverá uma educação de qualidade.

A identidade do educador voltada a atender as necessidades do campo até hoje têm sido desenvolvida pelos professores atrelados aos Movimentos Sociais, mas o que queremos discutir é a construção ou falta desta identidade dos docentes não integrados aos diferentes Movimentos, o que segundo Nascimento:

São professores [...] que possuem um alto grau de desvinculação com o meio sócio-econômico dos alunos/as que impedem um processo de interagibilidade, conhecimento e dialeticidade que se formam na história de cada identidade. (2004, p.2).

Porém, percebe-se que ela é possível e não está restrita aos professores atrelados aos Movimentos Sociais, pois segundo Pimenta "é na leitura crítica da profissão diante das realidades sociais que buscam os referenciais para modificá-la" (2002, p. 19). Essa perspectiva nos remete ao pensamento de que a identidade do profissional do campo pode ser construída sem sua inserção aos Movimentos Sociais, desde que eles sejam conhecedores dos projetos educativos do campo e que possam se integrar de forma efetiva na comunidade a qual estão inseridos, contribuindo para o processo de inclusão e na construção de uma verdadeira cidadania para os sujeitos do campo. Contudo, faz-se indispensável uma análise nas afirmações de Nascimento: 
[...] os educadores são vítimas de um sistema educacional que desvaloriza o trabalho da docência, principalmente, os coloca num circulo vicioso e perverso. Isto faz gerar uma conseqüência problemática: como vítimas (os educadores/as) constroem novas vítimas, os educando/as das escolas do campo. (2004, p.12).

São diversos os problemas enfrentados por este professor que está nas escolas rurais, uma vez que seus direitos são negados, sua condição de trabalho não é favorável, não lhe proporcionam uma formação adequada que possibilitem sua identificação com o campo, não evidenciam seu papel dentro da comunidade, e além destes fatores, os mesmos sofrem uma discriminação por serem professores rurais, o que origina um certo preconceito da sociedade frente a estes profissionais. Muito embora estes tenham ganhado espaço a partir I Conferência Nacional por uma Educação do campo, o que se pode perceber é que as metas traçadas por esta conferência só estão sendo seguidas e aplicadas apenas nos estabelecimentos os quais os Movimentos Sociais estão inseridos. Daí dar-se a necessidade de políticas voltadas para atender estes profissionais, de maneira que os possibilitem um reencontro com a sua identidade.

Na prática, várias circunstâncias impossibilitam a construção da identidade dos professores do campo não atrelados aos Movimentos Sociais, visto que estes não encontram referências positivas diante a sua profissão na sociedade brasileira. Essas circunstâncias associadas aos problemas de base que circundam a educação do campo, impossibilitam ainda mais na efetivação de uma identidade vinculadas aos projetos educativos voltada para os anseios e expectativas dos sujeitos do campo.

\section{O contexto da formação continuada dos professores de Gameleira}

A formação continuada é um valioso instrumento para o aperfeiçoamento dos profissionais que estão envolvidos diretamente com a educação, em especial aos professores, a mesma deve ter seus objetivos coerentes com a realidade a qual os docentes estão inseridos, possibilitando um encontro entre suas teorias e práticas pedagógicas, bem como evidenciando seu papel dentro da sociedade, propiciando um reencontro com a sua profissão docente. Para tanto é necessário que os executores de tais formações estejam cientes da realidade e necessidades dos professores, para que 
estas se traduzam em mudanças significativas em sala de aula e na sua vida enquanto professor.

Salientamos que a educação oferecida à população rural pelo município de Gameleira - PE, ainda concentra-se na concepção de uma educação rural, o qual tem seus princípios voltados a oferecer uma educação compensatória ou equivalente ao da zona urbana, refletindo na prática que é destinada ao povo do campo. Neste sentido, afirma Silva (2007), ao discutir o problema da educação no campo:

A principal dificuldade para que esta realidade se torne possível está justamente no fato de que paralelo a uma educação no campo coexiste ainda um projeto oficial de educação rural que se faz nos moldes da falta de sensibilidade e baixa formação acadêmica e política dos docentes, na má estrutura física das escolas e na ausência de uma concepção de educação que permita formar cidadãos críticos (p.101).

No que se refere à formação continuada oferecida pelo município de Gameleira - PE existe uma desarticulação entre os discursos e práticas executadas, as mesmas estão conduzidas apenas como cumprimento de carga horária, uma vez que seus objetivos principais não estão sendo cumpridos e nem alcançadas, visto que estas formações buscam auxiliar o docente em suas atividades diárias, e acima de tudo evidenciando seu papel dentro do grupo ao qual seu trabalho deve direcionado. Além deste problema os professores ainda tomam essas formações com imposição do sistema educacional do município, haja vista que não existe nenhuma motivação para realizações destes momentos, que vislumbrem efetivas mudanças.

Outra questão bastante preocupante é a freqüência das realizações destas formações, pois estas dão-se uma vez no início de cada ano, com professores da rede pública e particular do município. Porém, no ano de 2007 o problema é ainda maior, visto que até o presente momento não houve nenhum momento de formação que possibilitasse aos professores um aperfeiçoamento e nem um encontro de novas práticas. Esta questão reflete diretamente no trabalho do professor, uma vez que estes profissionais não encontram motivação para reflexão do ato educativo.

As formações proporcionadas pelo município são executadas por empresas que fazem assessoria educacional, os mesmos recebem informações restritas do público a ser atendido para elaboração de temas e objetivos do encontro, ficando a Secretaria de 
Educação responsável apenas para organização do espaço físico para a realização do evento, recebendo dias antes a programação do encontro dos professores, não tendo esta nenhuma interferência significativa neste processo.

O problema torna-se mais agravante se consideramos a ausência de uma formação específica para os professores regentes nas escolas rurais, visto que as existentes são direcionadas para todo o corpo docente do município. Frente aos diversos problemas vivenciados por estes profissionais na execução de seu trabalho, o mesmo têm que se submeter a uma formação que não condiz com a realidade na qual estão imersos em suas práticas diárias.

Além do descaso com a formação dos profissionais do campo, ainda existe a desarticulação das propostas em relação às Diretrizes Operacionais para a Educação Básica das Escolas do Campo, os quais orientam que as políticas de formação continuada deverão propiciar os estudos a respeito da diversidade dos alunos e o contato com práticas pedagógicas que valorizem a diversidade cultural e os processos de interação e transformações do campo, dentre outros, as aspectos que não são considerados quando na elaboração das propostas de formação continuada para os professores do campo no município da Gameleira.

Em outros termos, o contexto da formação continuada do município de Gameleira - PE mostra-se fragmentada sem uma seqüência lógica, rompendo com uma continuidade que poderia favorecer aos professores e conseqüentemente a qualidade de ensino oferecida, em particular a população do campo. Isto ocasiona um desinteresse de alguns professores, que vêm esta formação apenas como cumprimento do calendário escolar, e não como um aperfeiçoamento de suas práticas e sua renovação como profissional, ou seja, o professor ao observar o não cumprimento destas atividades em relação à carga horária, temas, e objetivos, passa então a freqüentá-las por obrigação de seu trabalho.

Tais desestímulos são ocasionados também pela concepção de educação rural que dão origem a estas formações para os professores da zona rural do município, visto que o mesmo não são "conhecedores" dos princípios e finalidades que norteiam a educação no campo. Isto se dá pelo fato de que nos últimos anos não houve uma formação direcionada a atender as necessidades e anseios destes profissionais. Uma vez que as temáticas contempladas nestes encontros dão conta de suprir apenas teoricamente 
as necessidades genéricas da educação infantil, o ensino fundamental I e II e o EJA na realidade da educação urbana, deixando de lado os problemas vivenciados por estes profissionais no cotidiano escolar das escolas rurais, conseqüentemente ocorrendo um descontextualização das práticas pedagógicas referente à realidade a que estão inseridos.

Em outras palavras, a orientação dada aos professores do campo em programas de formação continuada do município se apresenta equivalente ao da zona urbana, se considerados temas trabalhado e metas a serem seguidas. Face a este quadro é evidente a carência destas formações e a necessidade do estabelecimento de objetivos coerentes com a sua realidade, desenvolvendo uma proposta de educação verdadeiramente no campo e do campo.

Diante dos fatos, é necessário que estas formações continuadas sejam repensadas, e modificadas para atender as reais condições dos professores, tomando como partida a realidade que eles estão inseridos, para que haja verdadeiramente uma formação contínua, sem fragmentação, o que resultaria na melhora da qualidade de ensino oferecida para a população, seja ela rural.

\section{O que os professores de escolas rurais pensam sobre a formação continuada?}

A educação oferecida à população rural sempre foi alvo de críticas que se direcionavam a sua degeneralização e conseqüentemente os professores eram apontados como um dos responsáveis de seu fracasso, o que resulta numa aversão dos docentes as escolas rurais, pelas condições de trabalho que lhes são impostas.

Daí verifica-se a importância de uma formação direcionada a atender as necessidades dos professores de maneira que os possibilitem a sua identificação com a causa do campo, porém, percebe-se que estas não vêm sendo praticadas pelo município de Gameleira, pois após as análises das entrevistas e observações realizadas, constatouse que estes encontros não têm contribuindo para suprir as dificuldades primordiais dos professores regentes nas escolas rurais.

Por tudo isto, o professor percebe um grande vazio frente a estes encontros, embora eles sejam conhecedores da sua importância para o aperfeiçoamento profissional, estes não se sentem estimulados para freqüentar e participar efetivamente dos debates realizados, este descaso pode ser confirmado nos depoimentos da 
Professora 3, em que aponta que as formações não atendem nenhum tipo de necessidade dos professores da zona rural:

[...] meu município não faz uma formação continuada, nem $50 \%$ chega atender as necessidades, porque muitas vezes a gente vai lá não querendo receitas, porque a formação não dá receitas ela indica, ela media, vai mediar você. [...] no meu ponto de vista não atendeu nenhum necessidade do professor da zona rural é diferente, a realidade é bem distante da zona rural.

Este pensamento está presente em todos os discursos dos professores entrevistados, embora alguns tenham dito que estes encontros têm contribuído para sua formação, os mesmos são contraditórios quando afirmam que existe uma lacuna no direcionamento destas, pois não se trabalham com as dificuldades mais latentes deste profissional. Podemos reafirmar tal constatação com a fala da professora 1, em que ela acentua esta dificuldade como algo que impossibilita o desenvolvimento de seu trabalho em salda de aula:

Eu acho muito fraco [...] a gente fica do mesmo jeito, não inovavam nada, não mudou nada, essas capacitações que a gente teve não inovou em nada.

Como pode ser observado, existe uma fragmentação e uma descontinuidade destes encontros realizados pela Secretaria de Educação do município de Gameleira $\mathrm{PE}$, conseqüentemente os professores desacreditam nas intenções reais de tais processos e começam a freqüentá-los por imposição do sistema educacional, e não por acreditarem melhorias em suas práticas pedagógicas.

É indispensável que as formações continuadas ofereçam ao seu público propostas direcionadas as reais vivências que cada profissional se depara, e percebemos que essa importância se evidencia nos depoimentos de algumas professoras quando falam da necessidade de que a formação abrangesse a realidade e o aperfeiçoamento dos profissionais da zona rural, os quais não são contemplados nas propostas oferecidas aos profissionais da educação, como citam as professoras:

Entrevistada $2:[\ldots]$ principalmente para zona rural também é regular porque também não tem essa preparação do professor 
do campo, não se tem essa preparação voltada para o campo não tem. [...].

Entrevistada 3: [...] no meu ponto de vista não atendeu nenhum necessidade do professor da zona rural é diferente, a realidade é bem distante da zona rural [...].

Entrevistada 4: [...] Assim, ele receber uma melhor formação, ser mais bem preparado receber instruções que ele possa desenvolver um bom trabalho na sala de aula, por que na medida que se tem uma formação continuada bem desenvolvida que atenda todas as necessidades, ai o trabalho dele na sala de aula vai melhorar.

Os professores destacam ainda alguns temas que poderiam ser trabalhados, porém os mesmos limitam-se a dar sugestões apenas referentes a conteúdos, mesmo que a pergunta que fizemos fosse direcionada a temas referentes ao professor, isso mostra que esses profissionais sentem necessidades de algo para o seu trabalho, mas não têm consciência do que tem que ser feito diante da sua prática. No entanto, apenas duas professoras se posicionaram sobre a importância de se trabalhar com temas relacionados ao papel do profissional que estão inseridos na realidade das escolas do campo, a professora 3 depois de ter dado sugestões de temas que abordava em sua prática diante dos conteúdos e com nossas intervenções que reforçava a idéia de temas direcionados ao professor da zona rural, mencionou que precisam ser trabalhados temas que: "Conscientizasse sobre o nosso papel enquanto educador" respondeu prontamente que: "Pra mim professor, , valorização para os professores da zona rural, por que não existe".

Estes profissionais muitas vezes não têm clareza do que é formação continuada e reuniões pedagógicas, esse fato se evidencia pela ausência de assiduidade destes encontros de formação que são primordiais para o desenvolvimento do profissional integrado na educação de forma efetiva. Essa assiduidade vem junto da cobrança na quantidade de tempo desses encontros, pois segundo alguma entrevistada tem sido pouco para suprir as necessidades dos professores e em especial os da zona rural.

Frente às exposições dos depoimentos dos professores da zona rural sobre a formação continuada, pudemos constatar que esta precisa se adequar às necessidades e dificuldades dos professores para que possa atender suas expectativas e anseios, a fim de contribuir de forma ativa, propiciando as estes profissionais construir sua identidade e começarem a colaborar no processo de formação de cidadãos crítico-reflexivo. 


\section{Os fatores que inviabilizam a construção de uma identidade positiva sobre a profissão.}

O professor de um modo geral vive na expectativa de dias melhores com relação a sua profissão, se agarrando em esperanças que possam contribuir com a continuidade de sua vida docente, isto faz gerar alguns conflitos que impossibilitam a construção de uma identidade profissional.

São inúmeros os fatores que inviabilizam a construção de uma identidade positiva dos professores, em especial aqueles regentes em escolas rurais, pois além de enfrentar problemas referentes à sua profissão, estes têm que se confrontar com situações mais emergenciais do que os encontrados na zona urbana.

Se direcionado tais fatos para a realidade dos professores do município de Gameleira - PE, percebemos após as análises das entrevistas e observações, que estes não encontram nenhuma referência positiva em relação a sua profissão no município, que os possibilitem a construção de uma identidade vinculada às propostas que deve ser direcionada a população rural. Segundo Guimarães: “a identidade profissional do professor tem sido referida predominantemente a maneira como a profissão docente é representada, construída e mantida socialmente". (2004, p.59).

Porém, não se pode exigir dos professores uma identificação com algo que não tem conhecimento, isto tem sido ocasionado pela ausência de uma formação continuada que os possibilitem o reconhecimento de seu papel dentro da comunidade ao qual está inserida, resgatando seus valores, sua auto-estima e acima de tudo os motivando para a continuidade de seu trabalho enquanto professor de uma comunidade que foi por muito tempo excluído das políticas públicas do Brasil. Desta forma:

Não posso estar seguro do que faço se não sei como fundamentar cientificamente a minha ação, se não tenho pelo menos algumas idéias em torno do que faço, de por que faço, para que faço. Se pouco ou nada sei sobre ou favor de que e de quem, de contra quê e contra quem faço o que estou fazendo ou farei. (FREIRE, 2003, p.61).

Tais fatos têm ocasionado a um caminho não tão favorável a sua profissão, refere-se ao comodismo, pois ao admitirem tais situações se conformam com o descaso, nem reivindicam seus direitos e nem buscam uma auto-formação que possam contribuir 
para o seu trabalho enquanto docente. Os professores das escolas rurais de Gameleira se enquadram perfeitamente neste panorama, pois em todos os depoimentos coletados através da entrevistas, percebemos que estes se sentem incomodados com a Secretaria de Educação frente à realização dos encontros destinados a eles, porém acabam aceitando e terminam não tendo suporte suficiente para atender as necessidades mais gritantes destas comunidades.

Além do problema descritos, percebemos que parte de nossa amostra são professores que se encontram desmotivados com relação ao futuro de sua profissão, ocasionadas muitas vezes pelos baixos salários, falta de reconhecimento dos políticos e da sociedade em geral, a negação de seus direitos e principalmente a falta de reconhecimento de seus alunos, visto que a estes o direcionamento de todo o seu trabalho. Os discursos dos professores parecem semelhantes ao afirmarem que a profissão docente não é mais respeitada e nem tampouco valorizada, isto gera uma série de fatores que impossibilitam a construção ou até mesmo uma identificação profissional, oriundas de uma crise que insiste em permanecer afligindo a este de trabalhadores.

Para os professores rurais o problema é ainda maior, pois além de confrontar com os problemas vindas de sua profissão, estes têm que defrontar com realidades mais gritantes, tanto por parte da comunidade em que seu trabalho deve ser direcionado, como pelo preconceito a ele atribuído por se professor de uma comunidade tida como atrasada, o que gera uma inferioridade frente a sua profissão. Libanêo ilustra muito bem tais situações quando afirma:

É difícil aos professores assumirem os requisitos profissionais e éticos da profissão com os baixos salários, com a preparação profissional deficiente, com a baixa auto-estima que vai tomando conta de sua personalidade (2001, p. 90)

O pensamento de Libanêo reafirma as condições profissionais que se encontram os professores, se direcionado aos docentes da educação rural do município de Gameleira, este se enquadra perfeitamente no perfil aqui traçado, pois estes têm sofrido pela ausência de uma formação específica que atenda as suas reais necessidades, baixos salários e principalmente a baixa auto-estima, sendo esta última determinante na crise da identidade, conseqüentemente interferindo no processo de construção de uma 
identidade voltada para os anseios e necessidades dos educando das escolas rurais do município.

Em face deste quadro, existem outros elementos que direcionam para o desprestígio, desvalorização e desconfiguração destes profissionais, visto que a partir do momento que alguns mitos e imagens são direcionados a sua profissão, os mesmos não se sentem confortáveis diante de tais procedimentos. Algumas imagens são historicamente atribuídas a estes profissionais principalmente quando se refere às professoras como "tia" e quando direciona o magistério como atividade adequada às mulheres. Segundo Freire:

A tentativa de reduzir à professora a condição de tia é uma "inocente" armadilha ideológica em que, tentando-se dar a ilusão de adocicar a vida da professora o que tenta é amaciar a sua capacidade de luta ou entretê-la no exercício de tarefas fundamentais. (2003, p.25).

Contudo, estes mitos e imagens tendem confundir estes profissionais em relação a seu real papel com profissional da educação, muito embora estes não tenham sido encontradas como algo prejudicial nos depoimentos de nossas amostras, percebemos que isto se dá pelo fato histórico em que a docência é tida como uma atividade maternal.

Outra questão bastante crucial a ser considerada na construção de uma identidade profissional, em especial dos docentes das escolas rurais, é a insistência de alguns governantes em permanecer com a concepção de uma educação rural a ser oferecida a esta comunidade. Desta maneira, as propostas destinadas aos professores permanecem arcaicas e principalmente excludentes frente às necessidades encontradas no desenvolvimento de seu trabalho, conseqüentemente ocasionando momentos de incertezas e baixa auto-estima com relação a sua profissão.

Tendo por base as análises dos documentos e das entrevistas, percebemos que estes problemas vêm perpassando a história do município de Gameleira, o qual ainda se predomina uma educação rural, negando a este o direito de uma perspectiva e ascensão profissional diante a comunidade a qual seu trabalho deverá ser direcionado. Assim, tais procedimentos podem ocasionar uma crise de identidade ou até mesmo a impossibilidade da construção de uma identidade positiva, voltada para os projetos educativos do campo. 
Além destes fatores, podemos salientar a falta de credibilidade, os baixos salários, a deficiência de um a formação inicial, a falta de prestígio da comunidade em geral, refletindo diretamente na possibilidade da construção de uma identidade voltada a atender as verdadeiras necessidades dos sujeitos que vivem e sobrevivem do campo.

Contudo, é necessário que sejam analisadas as condições de trabalho que estes professores estão sendo submetidos, oferecendo oportunidades de ascensão profissional, buscando a implementação de políticas de valorização do professor, e que estas sejam efetivamente colocadas em prática, para que estes se reconheçam com educadores de um povo que necessita de oportunidades, oportunidades estas transformadas em mudanças significativas capazes de transformar uma ideologia ainda tão predominante em nosso país.

\section{Referências Bibliográficas}

BRASIL. Diretrizes Operacionais para Educação nas Escolas do Campo. 2002.

BAUER, Martin W., GASKELL, George \& ALLUM, Nicholas C. Qualidade, Quantidade e Interesses do Conhecimento - Evitando Confusões. In: BAUER, Martin W., GASKELL, George. Pesquisa qualitativa com texto, imagem e som - um manual prático. Rio de Janeiro: Vozes, 2002.

CALDART, Roseli Salete. Pedagogia do Movimento Sem Terra. $3^{\text {a }}$ Ed. São Paulo: Expressão Popular, 2002.

COLOGNESE, S. A., MÉLO, J. L. B. de. A técnica d Entrevista na Pesquisa Social. In: Pesquisa Social Empírica: Métodos e Técnicas. Cadernos de Sociologia, Porto Alegre, PPGS/UFRG, v. 9, 1998.

FRANCHI, Eglê Pontes (org). A causa dos professores: Campinas, SP: Papirus; 1995. (Coleção magistério: Formação e trabalho pedagógico).

FREIRE, Paulo. Professora sim, tia não: cartas a quem ousa ensinar. $14^{\circ}$ edição. São Paulo: Editora Olho d'Água, 2003.

GUIMARÃES, Valter Soares. Formação de Professores: Saberes, Identidade e Profissão. Campinas, SP: Papirus, 2004.(Coleção entre nós professores).

HAGUETTE, Tereza Maria Frota. Metodologias Qualitativas na Sociologia. $10^{\mathrm{a}}$. Ed. Petrópolis: Vozes, 2005. 
LIBÃNEO, José Carlos. Adeus professor, adeus professora?: novas exigências educacionais e profissão docente. $5^{\circ}$ ed. - São Paulo: Cortez, 2001. (Coleção Questões de Nossa época, v.67).

LOPES, Luíz Paulo da Moita. (Org). Discursos de Identidades: discursos como espaço e construção de gênero, sexualidade, raça, idade e profissão na escola e na família. Campinas, SP: Mercado de Letras, 2003.

MEKSENAS, Paulo. Existe uma origem da crise de identidade do professor? Revista Espaço Acadêmico - no 31 - Dezembro de 2003 - Mensal - ISSN 1519.6186. Disponível em: http: //espaçoacademico.com.br/031/31cmeksenas.htm. Acesso em: 30/03/2007.

NASCIMENTO, Godoy Claudemiro. Educação, cidadania e políticas sociais. Revista Iberoamericada de Educación. 2004.

PEREIRA, Júlio Emilio Diniz. Formação de Professores - Pesquisa, representações e poder. Belo Horizonte: Autentica, 2000.

PIMENTA, Selma Garrido (org). Formação de professores: saberes da docência e identidade do professor. São Paulo. Cortez, 2002.

RUDIO, Franz Victor. Introdução ao projeto de pesquisa científica. $23^{\mathrm{a}}$ ed. Petrópolis: Vozes, 1986.

SILVA, Ezequiel Theodoro da. Professor de $\mathbf{1}^{\mathbf{0}}$ grau: identidade em jogo. Campinas, SP: Papirus, 1995. (Coleção Magistério: formação e trabalho pedagógico).

SILVA, Tarcísio Augusto A. da. A educação no campo: uma reflexão freiriana. In: REYDSON, Deyve. COSTA, Fernanda. Et al. Política e educação em Paulo Freire Olhares sobre um caminho. Recife, UFPE, 2007.

SOUZA, Aparecida Néri. Sou professor, sim senhor!: Representações do trabalho docente. Campinas - SP: Papirus, 1996.

VEIGA, Ilma Passos Alencastro, CUNHA, Maria Isabel da.(Org). Desmistificando a Profissionalização do Magistério. Campinas, SP: Papirus, 1999. (Coleção Magistério: Formação e Trabalho Pedagógico). 